\title{
Structural Fire Engineering of Complex Frames by Means of Micro-Computer Application
}

W. KLINGSCH and F.-W. WITTBECKER

Wuppertal University

Pauluskirchstr, 7

D-5600 Wuppertal 2, FRG

\section{ABSTRACT}

A numerical method is presented which renders possible realistic structural fire engineering practice; using micro computers is possible.

Program structure and its numerical principles were discussed including computer orientated formulation of material properties. Physical and geometrical nonlinearities are taken into account. Accuracy is demonstrated in comparison with full scale ISO-fire test results.

Analysis of complex frame behaviour is shown with a multi storey frame under local fire.

For practical application in scructural fire design there are no restrictions in materials and fire characteristics.

KEYWORDS: NUMERICAL MODELLING; STRUCTURAL FIRE ENGINEERING, COMPLETE FRAME ANALYSIS, MATERIAL PROPERTIES FORMULATION 


\section{INTRODUCTION}

Most finite element programs are basing on a linear elastic material behaviour. This leads to thermal and mechanical independend results of the computation. Only effects of II. order theory are taken into account (equilibrium - deformation interaction).

In fire case connected structural members lead to a redistribution of forces mainly effected by stiffness differences inside the structure and between the cold and the hot structural members.

Because of thermal and load dependend cross section stiffness an integrated iteration process to adjust the internal froces to the load dependend deformations and forces (theorie II. order) is necessary. This is the main reason, that it has been regarded in the past hardly possible to calculate behaviour of complete structures in fire case by means of micro-computers and in a realistic way. Software for a simplified analysis is not considered here.

Today we have some programs which can solve the problem with a more or less extensiv numerical expence and by this by larger computers. The programs which have been developed to calculate complete structures $/ 3,4 /$ in fire case on a physical realistic basis are running only on big computers because the necessary storage capacity is too large and the computation time is so long that an economic use of microcomputers seemed to be impossible.

\section{MATHEMATICAL PRINCIPLE OF A MICRO - COMPUTER ORIENTATED SOLUTION TECHNIQUE}

All numerical methods of structures in fire case are basing on a two dimensional discretisation of the cross section. To analyse system behaviour discretisation has to be extended to a three dimensional discretisation.

Computer programs for structural fire engineering of today can bei devided into two groups respecting the numerical methods and the computing structure: direct and indirect methods.

The direct method which is modeling the continuum by a corresponding number of finite elements totaly, leads very fast to the rate of the computer capacity.

The indirect method at first summarizes the single component stiffnesses of the cross section to an integrated stiffness. Full structural member analys is a step by step procedure: Thermal analysis of the cross sections is followed by mechanical cross section analysis. Basing on these results the system analysis can be done taking into account effects of deformation (II. order theory). 


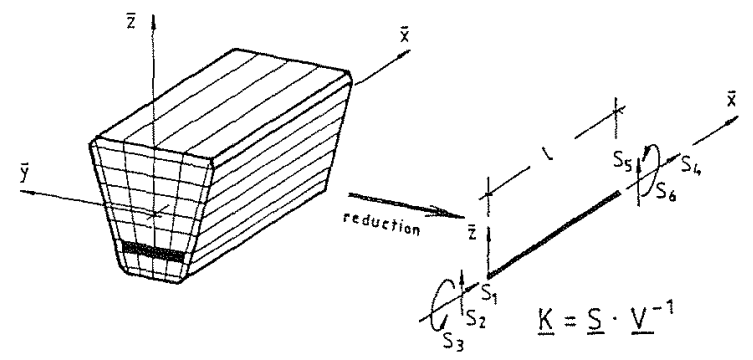

Figure 1. Summation of single members to a resulting stiffness $\mathrm{T}=\mathrm{T}(\overrightarrow{\mathrm{y}}, \overrightarrow{\mathrm{z}}) ; \mathrm{T}(\overline{\mathrm{x}})=$ const.

The resulting cross section stiffness values are connected directly with the mathematicaly forumulated stress versus strain relations of the materials. This allows to take into account all physical nonlinearities of the mechanical material properties (like strength and strains) or disctoninuous material behaviour (like cracking or crushing of concrete, yielding of steel etc.) effected by their temperature dependencies or internal load redistribution in a realistic way.

Further calculations can be done with a common beam finite element with 6 degrees of freedom (3 at each node regarding plain systems). Effects of II. order theory deformation are included using a geometric nonlinear stiffness matrix formulation.

\section{A MICRO COMPUTER ORIENTATED MATHEMATICAL FORMULATION OF MATERIAL PROPERTIES}

Conformity of computed results with reality depends on the quality of stress versus strain formulations. A computer orientated description of stress-strain relations needs a general analytical formulation for the whole temperature range. Creep effects can be included in such a formulation.

Thermal strains which are distributed over the cross section similar to the temperature field must be taken into account for a realistic numerical analysis but have to be separated from the mechanical properties.

Material laws do not claim to describe exact material behaviour in the sense of material science. They are calculation values or calculational functions of material behaviour with a number of simplifications. Nevertheless, for numeriical simulations they can describe real structural behaviour in a very proper way.

Development of numerical formulation of material laws in a micro computer orientated way is illustrated for concrete, as an example. 
The following equations use a broken rational polynom and lead to a sood computer orientated formulation which avoids the necessity of a large storage capacity and allows very small computation time as result.

$$
\begin{array}{ll}
\sigma_{b}(\varepsilon, T)=\frac{\left(\frac{\varepsilon}{\varepsilon_{0}(T)}\right)\left(A+\frac{(B-1) \cdot \varepsilon}{\varepsilon_{0}(T)}\right)}{1+\left(\frac{E}{\varepsilon_{0}(T)}\right)\left(B+\frac{(A-2) \cdot \varepsilon}{\varepsilon_{0}(T)}\right)} \cdot \beta_{R}(T) & \text { I } \\
\sigma_{b}(\varepsilon, T)=\frac{(a+1) \cdot \varepsilon\left(\varepsilon_{0}(T)\right.}{a+\left(\varepsilon / \varepsilon_{0}(T)\right)^{b}} \cdot \beta_{R}(T) & \text { II }
\end{array}
$$

Equation $I$ is basing on the formulation by Sargin $/ 5 /$, equation II on the equation by Tulin/Gerstle $/ 6 \%$. Both equations were presented for normal conditions and have been enlarged for high temperature conditions.

The shapes of the functions are changeable by varying the temperature independend parameters $A$ and $B$ respectively a and $b$.

The parameters $E O(T)$ and $B_{R}(T)$ are presented as functions with temperature dependency and shown in fig. 2 for the whole temperature range.

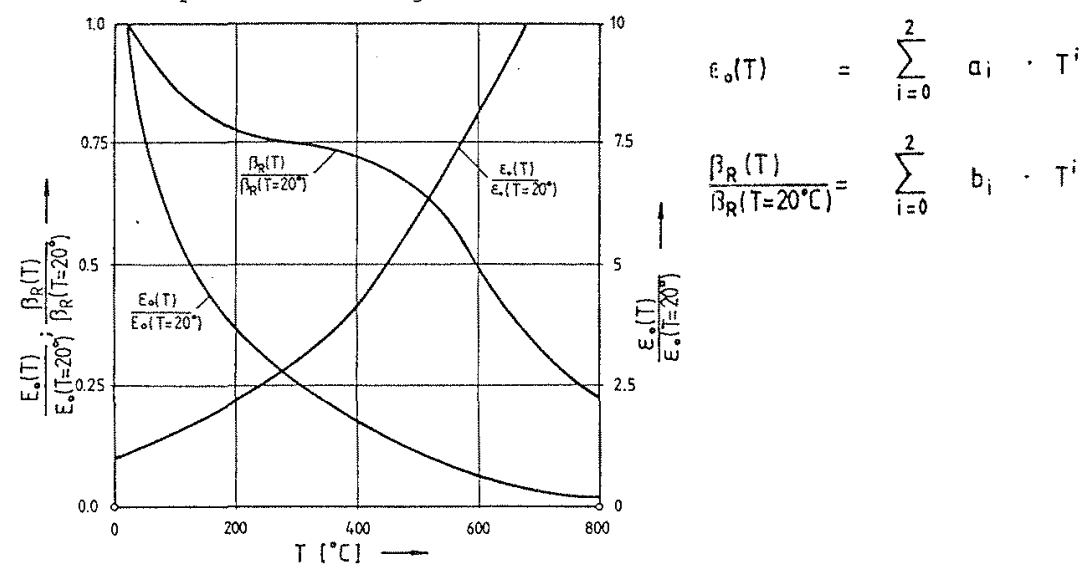

Figure 2. Temperature dependend material behaviour.

A stress strain relationship for steel using an elliptic functional formulation has been developed by Schaumann $/ 4 /$. These equations allow very quick calculations of temperature depending stress values corresponding to strain values. Details about steel material laws can be found in /4/. 


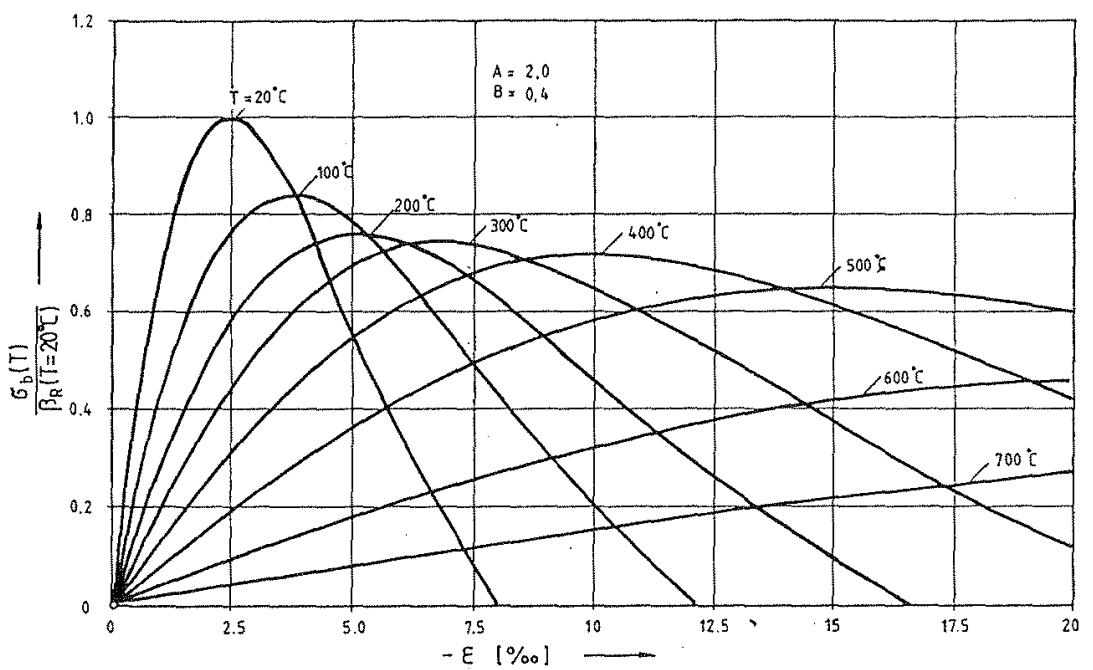

Figure 3. Temperature dependend stress-strain relationship of concrete $/ 2 /$.

\section{MICRO-COMPUTER ORIENTATED MAIN PROGRAM STRUCTURE}

Micro-computers of today have a 16 bit cpu as minimum up to 32 bit within the last generation and a storage of at least $256 \mathrm{kB}$ up to $4 \mathrm{MB}$. But this enormous storage unfortunately can only activated partly by Dos-versions up to Dos 3.3 .

For realistic calculation of structures in fire case it is necessary to subdivide the cross section into a mesh of about up to 800 elements; it depends on the type of the structural member like steel, concrete or composite cross sections. In combination with the discretisation of the structure along its beam axis ( $x$-axis, see picture $l$ ) even with the advantagous indirect calculation method storage effectiv capacity of micro computer isn't big enough to keep all variables simultaneously.

Because no interactions between temperature development and structural analysis must be taken into account at the actual state of fire engineering, thermal analysis can be seperated from mechanical analysis.

By this as a first step, temperature distribution of the cross section can be calculated completely and can be stored in a temporary external file. Consequently complete storage capacity can be used for mechanical analysis of cross section and complete system. The temperature dependend parameters will be read from the temporary file on the floppy- or hard disk. 
In case of computing only single members there is another simplification which avoids need of big computer storage and computing time. Single members mostly are loaded with nearly constant normal forces along their $x$-axis. That means that cross section calculation can also be separated from system analysis. Using this simplification cross section stiffness can be described for the complete range of bending moment capacity at each time step depending on the constant normal force of the structural member. This leads to the advantage of an easy iterative calculation process of the nonconstant stiffnesses which varies with increasing bending moments by theory II. order.

Realistic thermal analysis of a cross section up to $90 \mathrm{~min}$ ISO-fire takes about 5 cpu-minutes as everage when taking all nonlinear and temperature dependent thermal parameters into account. this value describes capacity of a computer which has an INTEL 8086 processor supported by a mathematical comprocessor 8087 ; the computer runs with $8 \mathrm{mHz}$. The complete thermal and mechanical analysis of a single member takes about $10 \mathrm{~min}$ cpu-time on such a micro-computer. Computation of ultimate load bearing capacity of columns has to be done by incremental increasing of the loads. Which extends cpu - time up to $20 \mathrm{~min}$ depending on the range of discretisation.

Harvard Computer Fire Code (HCFC) runs on micro computer without any problems which is well known. To calculate a complete fire scenario it takes about $30 \mathrm{~min}$ cpu-time. By this analysis of natural fire influences on structural members is possible on micro-computers.

\section{ACCURACY}

A lot of full scale fire tests on single structural members of different types are available to check validity of numerical procedures and the used mathematical formulations of material laws. Failure time comparison is rather good in general /2,7/ but this criteria alone is not strong enough.

Higher requirements on accuracy of the computer program must be satisfied for deformation analysis when extending from single structural member analysis to more complex systems.

Figure 4 shows two of the few full scale fire tests on half frames in reinforced concrete construction. The half frame has been calculated by the computer program ENSA / I/. Comparison of computet and measured deformations and failure times of a fire tested half frame in composite construction is shown in /2,7/. Such a half Erame takes about 2 hours cpu-time on a micro computer for the calculation of the complete deformation history using the indirect solution method. 

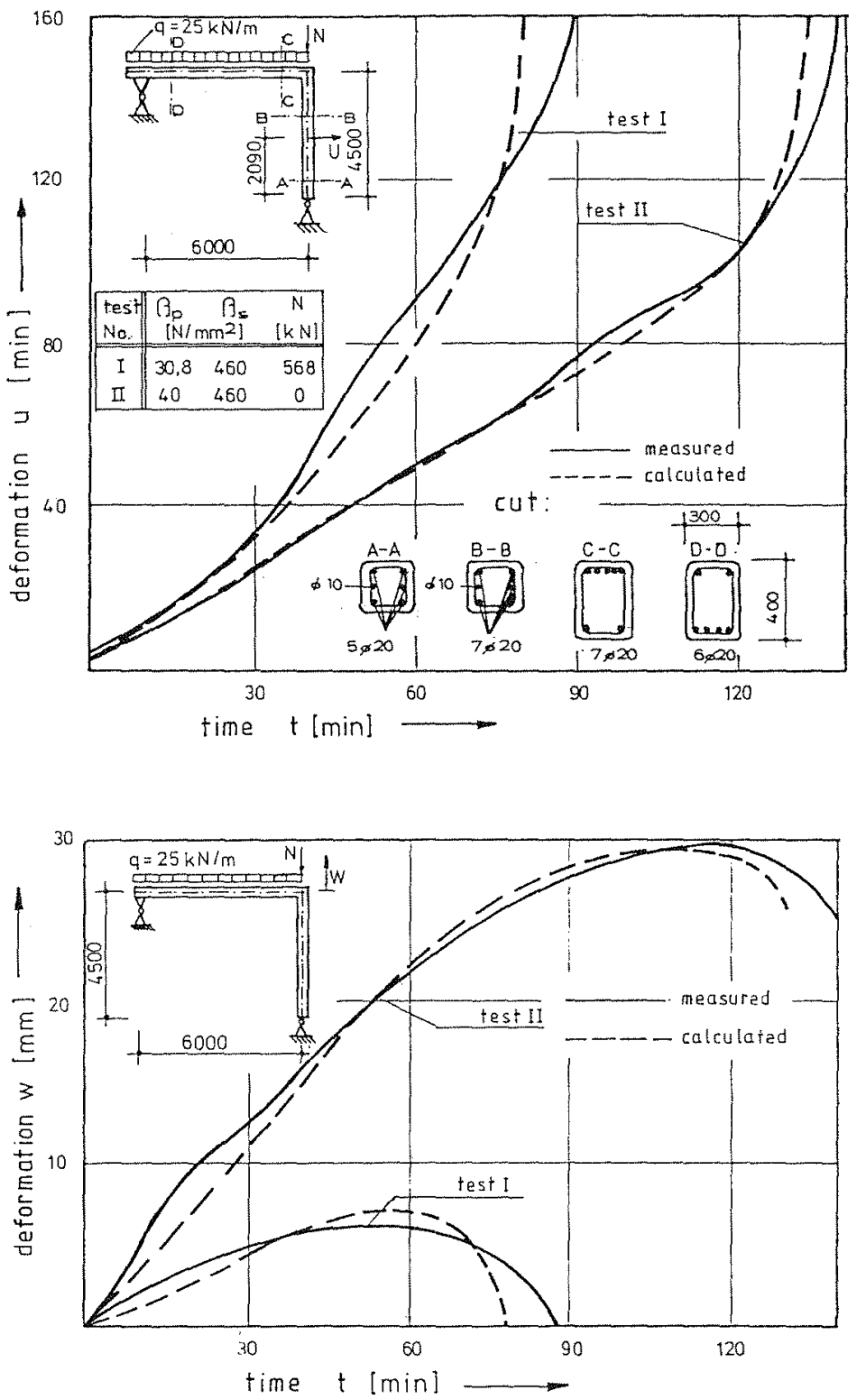

Figure 4 a and 4 b. Comparison between calculated and measured deformation of a half frame reinforced concrete construction (test results from /8/). 


\section{COMPLEX FRAME ANALYSIS}

To get a better understanding of the behaviour of a more realistic and by this a more complex frame under local fires, a frame structure of 3 stores and 3 bays has been analysed. All structural members - $T$ beams and columns - are designed as composite structural members. The slabs themself are of reinforced concrete and with shear connection to the beams. Plate effects were not considered.

system:
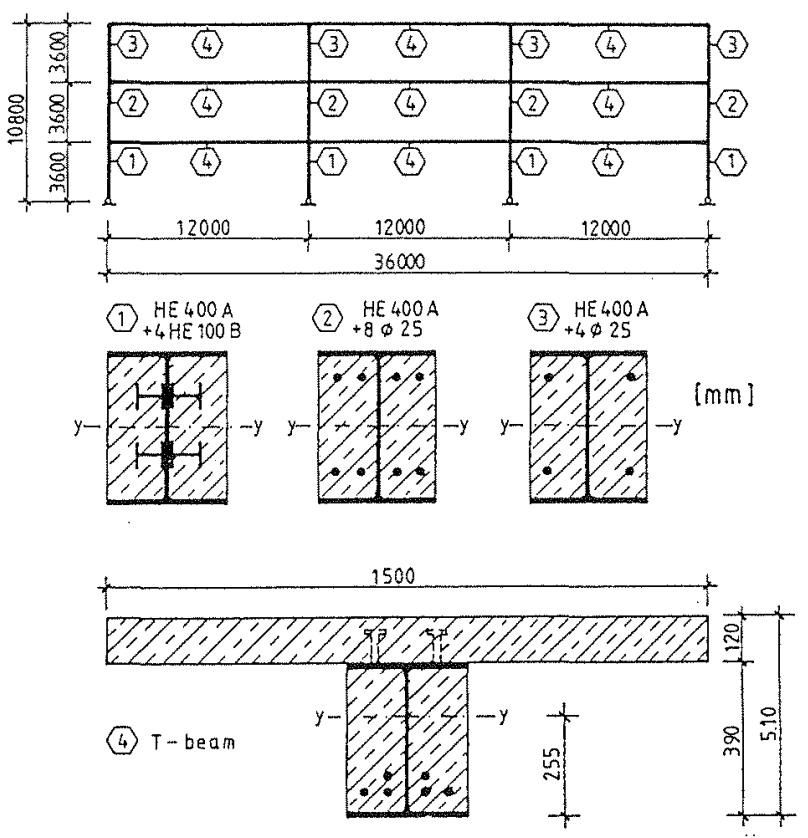

Figure 5. Types and dimensions of the calculated 3 * 3 frame.

picture 6 shows the time dependency of normal forces distribution of the beams caused by a local Iso - fire at the midale of the first floor. 

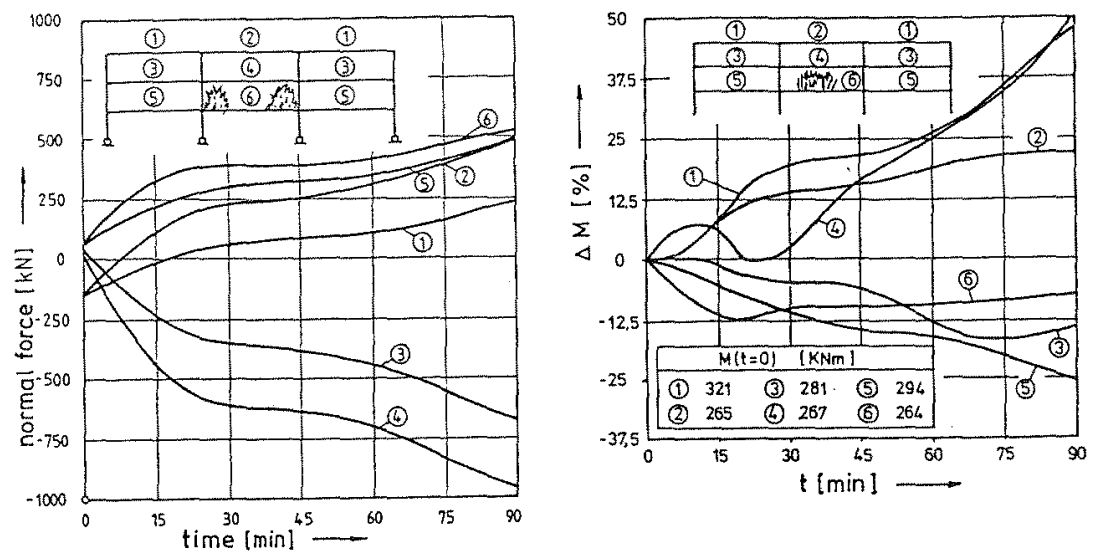

Figure 6. Time depending changing of the beam normal forces Figure 7. Time depending changing of the beam bending moments.

The time dependency of bending moments at the middle of the beams is shown in picture 7 .

It can be seen that there is not only a changing of the value of loading inside the structure effected by its internal restraining effects but also a changing of the signs of the loading. Within the meaning of a safety analysis these results give informations for good design:

Anchorage length of the reinforcement bars has to be adjusted to these features; beam/column connection has to be constructed for negativ bending moments under normal temperature conditions as well as for the positive bending moments in fire case to prevent early local collaps.

Caused by the restraining effects of the system there is also a redistribution of normal forces of the columns. Normal forces of edge columns are decreasing and normal forces of columns in the midale of the system are increasing up to $20 \%$ in this example. 


\section{CONCLUSION}

Structural fire engineering of today allows to calculate not only single structural members but also complete structures as well in an economic as in a realistic way by using micro computers. Key to good accuracy are advanced material orientated procedures. Validity of solution technique and mathematical description of material behaviour has been tested by numerical simulations of real fire tests on full scale structural members: beams, $T$ - beams, columns, frames - in steel, concrete or as composite elements. Safty analysis of complete structures for any fire scenario is possible as well as design optimization of cross sections and complete structures.

\section{REFERENCES}

1. Klingsch, W. and Wittbecker, F.-W.: ENSA - A computer program for complete structural analysis under normal temperatures and in fire case, Baustofftechnologie und Brandschutz, Wuppertal University, manual, 1986.

2. Wittbecker, F.-W.: Behaviour of transient heated complete structures of composite elements, research report (in German), Schriftenreihe Baustofftechnologie und Brandschutz, Heft 1, Wuppertal University, 1987.

3. Schleich, J.B.: ARBED recherches: Computer assisted analysis of the fire resistance of steel and composite concrete steel structures, research report, 1985.

4. Schaumann, P.: Analysis of steel structural members in fire case, research report No. 84-4 (in German), Institut für konstruktiven Ingenieurbau Ruhr-Universität Bochum, 1984.

5. Sargin, M.: Stress-strain relationships for concrete and analysis of concrete sections, Study No. 4, solid Mechanics division, University of Waterloo, Ontario, Canada 1971 .

6. Tulin, L.G. and Gerstle, K.H.: A contribution in: P. Desay and Krishman, S.: "Equation for the stress - strain curve of concrete", ACI journal, Proceedings Vol. 61, No 9 .

7. Klingsch, W. and Wittbecker, F.-W.: Numerical analysis of complete structures in fire cases: A contribution in: International meeting of fire research and test centres, ITSEMAP, Avila, 1986.

8. Haksever, A. and Walter, R.: Fire tests on reinforced concrete frames (in German). Arbeitsbericht 1975-77, Teil I, SFB 148, Technische Universität Braunschweig. 